\title{
SOFRIMENTO PATOGÊNICO DE AGENTES COMUNITÁRIOS DE SAÚDE EM UMA UBSF
}

\section{PATHOGENIC SUFFERING OF COMMUNITY HEALTH AGENTS IN A UBSF}

\author{
Maria Luiza Morais Rodrigues \\ Mestre em Saúde Ambiental e Saúde do Trabalhador - UFU \\ rmcondominio@gmail.com \\ Samuel do Carmo Lima \\ Prof. Doutor, do Instituto de Geografia - UFU \\ samuel@ufu.br
}

\begin{abstract}
RESUMO
O presente estudo busca compreender como o desenvolvimento do sofrimento patogênico de ACS se relaciona a organização do trabalho na Estratégia Saúde da Família em decorrência disto os objetivos específicos são: caracterizar o perfil sociodemográfico dos ACS participantes do estudo; analisar a organização do processo de trabalho sob o olhar do ACS e investigar as possíveis situações geradoras de sofrimento no trabalho do ACS. Para tanto se propõe uma abordagem qualitativa, conduzida por meio da observação participante e entrevistas individuais semiestruturadas com agentes comunitários da Estratégia Saúde da Família do Município de Uberlândia - MG. O material selecionado foi submetido à Análise de Conteúdo Temático e interpretado segundo o referencial teórico de Christophe Dejours sobre o sofrimento patogênico, a partir das seguintes categorias temáticas: a) Cotidiano de Trabalho dos ACS; b) Fontes de Prazer no Trabalho, c) Frustrações diante da incapacidade de resolver os problemas; d) Questões que interferem no processo de trabalho. O perfil sócio demográfico na pesquisa evidenciou um predomínio de ACS do sexo feminino, casadas, com ensino superior incompleto, adultos jovens e tempo de atuação entre 25 a 36 meses. A análise do cotidiano de trabalho dos ACS destacou que a principal atividade realizada dentre as que executa é a Visita Domiciliar e que outras determinadas pelo serviço divergem das prescritas pelo Ministério da Saúde. Ficou demonstrado que a satisfação profissional está intrinsicamente ligada a resolutividade de suas ações; a impotência e a incapacidade decorrente da ausência de suporte ou inexistência de ferramentas para atender as demandas da comunidade podem gerar no ACS o sofrimento. $\mathrm{Na}$ análise das questões que interferem no processo de trabalho dos ACS e que provocam angústia e insatisfação ficou demonstrado que a culpabilização de um agente externo pela não realização efetiva de seu trabalho é utilizada como estratégia de defesa. Apesar disso, os ACS estão afetivamente ligados ao seu trabalho, o que o torna fonte de sublimação e promotora de saúde. Diante disso propõe-se a reavaliação da organização do processo de trabalho.
\end{abstract}

Palavras-chave: Saúde do Trabalhador. Sofrimento Patogênico. Agente Comunitário de Saúde. Organização do trabalho.

\begin{abstract}
The present study aims to comprehend how the development of pathogenic suffering of Community Health Agents ( $\mathrm{CHA})$ is associated to the organization of work at the Family Health Strategy, as a result the specific objectives are: characterize the sociodemographic profile of the CHA participating in the study; analyze the process organization from the CHA's perspective and investigate the possible suffering situations at CHA's work. Therefore a qualitative approach is proposed, conducted by participant observation and semi structured individual interviews with community agents of the Family Health Strategy of Uberlandia- MG. The select material was submitted to a Thematic Content Analysis and interpreted according to Christophe Dejours' theoretical
\end{abstract}

Recebido em: 04/02/2019

Aceito para publicação em: 26/08/2019 
reference about pathogenic suffering, starting from the following thematic categories: a) Daily Work of CHA; b) Pleasure source at work; c) Frustrations coming from the inability of solving problems; d) Work questions interferences. The socio-demographic profile of the study shows predominant of females, married, with superior education incomplete, young adults and actuation time between 25 to 36 months in $\mathrm{CHA}$. The daily $\mathrm{CHA}$ work analyzes shows that the main activity, among others, is the Domicile Visit and others determined by divergent services of Health Ministry. It's shown that professional satisfaction is linked to the resoluteness of its actions; the impotence and inability due lack of support or inexistent tools to attend the demands of the community can lead CHA to suffering. Analyzing the interference questions on the work process of CHA is demonstrated that blaming external agents for the non-realization of one's work is the used as a defense mechanism in CHA. Despite, CHA are affectively connected to your work, which makes it a sublimation source and health promoter. On this, a revaluation on the organization ad work process.

Key words: Worker health. Pathologic Suffering. community Health Agents. Work organization.

\section{INTRODUÇÃO}

Parte da construção da humanidade em nós é forjada pelo trabalho, de modo que o trabalho é essencial à existência humana, ainda que produz satisfação e prazer e, ao mesmo tempo, insatisfação e sofrimento. Bruxel (2017) explicando isso diz que há uma dicotomia que se revela no trabalho que controe um ser humano e ao mesmo tempo o anula e o deteriora.

O trabalho é parte essencial da vida humana, sendo um meio de satisfação das necessidades de sustento, mas também busca de valorização pessoal (RAZZOUK et al., 2016). Além disso, compreende-se que as situações inerentes a um processo laboral inapropriadamente estruturado podem ocasionar danos à saúde dos trabalhadores (ANDRADE; DANTAS, 2015). Dessa forma, ao estudar a saúde mental no trabalho, também é fundamental a observação de problemas relacionados à organização da atividade laboral, como a valorização da função, a carga, o ritmo, a qualidade dos relacionamentos interpessoais, períodos de descanso, pressão de chefia, conteúdo das tarefas, horas trabalhadas, pois estas muitas vezes são as causas de agravos psíquicos (RAZZOUK et al., 2016).

Podem-se distinguir três principais correntes associadas ao estudo da Saúde Mental relacionado ao Trabalho. A primeira inclui teorias sobre o estresse, cujos estudos iniciais estavam voltados apenas para os aspectos fisiológicos e que posteriormente passaram a considerar fatores sociais como o trabalho. A segunda é composta por teorias que estudam o sofrimento mental relacionado com o trabalho. A terceira baseia-se no conceito de desgaste mental, que pode se constituir em um paradigma integrador das diferentes correntes teóricas (SELIGMANN-SILVA, 1994).

Este trabalho se desenvolve juntamente a segunda corrente teórica apresentada por SeligmannSilva (1994), especialmente ao buscar compreender a relação entre organização do trabalho e o desenvolvimento do sofrimento patogênico entre agentes comunitários de saúde. Dessa forma, dois conceitos são importantes para esse estudo: organização do trabalho e sofrimento patogênico.

Podemos dizer como Dejours (1987) e Dejours et al. (1994), que a organização do trabalho resulta da divisão de tarefas, na qual o trabalho é prescrito, com relações sociais e intersubjetivas, que exerce sobre o trabalhador uma ação específica, com impactos psicológicos, que podem trazer vivências de prazer e sofrimento. $O$ prazer ocorre quando o trabalhador vê sentido no que faz, 0 gratifica e traz reconhecimento, por isso o trabalho lhe faz bem, no corpo, na mente e nas relações sociais.

Moreno et al., (2010) diz que quando a organização adquire uma estrutura rígida, valorizando somente os aspectos econômicos, pode resultar em incompatibilização e conflito entre os desejos, os anseios e as vontades do trabalhador e a organização do trabalho. A dimensão psíquica do 
trabalho se revela por um conflito entre o trabalhador e o trabalho, de forma consciente ou inconsciente.

$\mathrm{Na}$ Psicopatologia do Trabalho, a normalidade considerada como equilíbrio psíquico entre o constrangimento do trabalho patogênico e as defesas psíquicas, a maioria dos trabalhadores não consegue preservar esse equilíbrio psíquico. A regra é o sofrimento e não a normalidade. Com essa constatação, as investigações nesta área centram-se, não mais na direção das doenças mentais, mas, nas estratégias elaboradas pelos trabalhadores para enfrentarem, mentalmente, a situação de trabalho (DEJOURS, 1994).

Quase sempre ocorre uma situação de conflito entre o trabalho prescrito (normas, regras, manuais) e o trabalho real. Quando o trabalhador consegue ser criativo e adapta-se a situação, quando consegue produzir resultados satisfatórios, neste caso, há um sofrimento criativo. Por outro lado, quando a situação não pode ser resolvida a contento, pode resultar em ansiedade e insatisfação. O resultado não satisfatório do trabalho traz frustração, insegurança, desvalorização profissional, estresse e esgotamento mental, o que se traduz em sofrimento patogênico. É claro que cada um reage diferentemente às situações que podem trazer vivências de sofrimento no trabalho (FREITAS; FACAS, 2013).

Além desses aspectos psicológicos, as condições de trabalho podem ser entendidas por meio do ambiente físico (luminosidade, temperatura, barulho); do ambiente químico (poeiras, vapores, gases e fumaças); do ambiente biológico (presença de vírus, bactérias, fungos, parasitas); pelas condições de higiene, de segurança e as características antropométricas do posto de trabalho nas indústrias; facilitaram o aparecimento de sofrimentos insuspeitos na vida dos operários (DEJOURS, 1998).

No caso dos Agentes Comunitários de Saúde, ocorrem diversas situações que podem promover sofrimento relacionadas às fragilidades existentes nos serviços de saúde, o desconhecimento das suas funções, a dificuldade em trabalhar de forma integrada com outros membros da equipe e a obrigatoriedade de trabalhar próximo ao local de moradia, o que incorre na perda da privacidade, na exposição à violência e ao medo (LOPES et al, 2012).

Um levantamento local sobre o número de atestados apresentados e a quantidade de dias em afastamentos referentes ao período de 2014 a 2016 mostrou que os Agentes Comunitários de Saúde (ASC) apresentaram 657 atestados, perfazendo um total de 2558 dias de afastamentos. Refinando esse levantamento, no momento em que foi realizado, uma das prestadoras do município a Fundação de Saúde do Município de Uberlândia - FundaSUS possuía contratos ativos com 179 ACS, mas 71 estavam afastados para tratamento de saúde.

O objetivo deste estudo é compreender como a organização do processo de trabalho se relaciona ao desenvolvimento do sofrimento patogênico dos ACS da Estratégia de Saúde da Família, no município de Uberlândia (MG).

A Estratégia Saúde da Família (ESF) é uma proposta de reorientação da Atenção Básica de Saúde (APS), e nela está inserido o Agente Comunitário de Saúde, que se propõe como novo modelo de atenção em saúde em desenvolvimento no Brasil.

A relevância deste estudo se faz na medida em que se conhecendo e identificando os fatores desencadeantes do sofrimento patogênico entre os ACS, será possível subsidiar a elaboração de estratégias de prevenção e promoção da saúde desses trabalhadores.

\section{METODOLOGIA}

A pesquisa foi desenvolvida por meio de uma abordagem qualitativa baseada em entrevistas semiestruturadas, na observação participante e de um questionário para caracterização sociodemográfica e profissional de ACS de uma Unidade de Saúde da Família com elevado índice de afastamentos no período de 2014 a 2016.

Para Minayo (2001), a pesquisa qualitativa trabalha com o universo de significados, de motivos, de aspirações, de crenças, de valores e de atitudes, o que corresponde a um espaço mais profundo das relações, dos processos e dos fenômenos que não podem ser reduzidos à operacionalização de 
variáveis. Aplicada inicialmente em estudos de antropologia e sociologia, como contraponto à pesquisa quantitativa dominante, tem alargado seu campo de atuação a áreas como a Psicologia e a Educação.

A pesquisa foi desenvolvida em Uberlândia, segundo município mais populoso do estado de Minas Gerais na Região Sudeste do Brasil. Localiza-se na mesorregião do Triângulo Mineiro. Sua população, segundo estimativas do Instituto Brasileiro de Geografia e Estatística (IBGE), era de 676613 habitantes em 2017 (IBGE, 2017). O município de Uberlândia possui 74 equipes de Estratégia de Saúde da Família da Rede SUS Municipal distribuídas em cinco grandes distritos Leste, Sul, Oeste, Central-Norte e Zona Rural. Estas equipes são responsáveis por uma cobertura de $43 \%$ da população. Cada equipe de ESF conta com 6 ACS perfazendo um total de 444 ACS.

Foi realizado um levantamento de dados primários quanto ao número de atestados apresentados e quantidade de dias em afastamentos dos 179 ACS que constavam no quadro de colaboradores, no período de 2014 a 2016 das Unidades Básicas de Saúde da Família sob a gestão da Fundação Saúde do Município de Uberlândia. Tal Fundação foi instituída pela lei complementar municipal n 558 , de 5 de março de 2013, considerada uma fundação pública dotada de personalidade jurídica de direito privado, sem fins lucrativos, de interesse coletivo e utilidade pública. Esse levantamento foi fundamental para a seleção da UBSF que foi incluída no estudo, uma vez que apresentava o maior número de atestados.

\section{Participantes da pesquisa}

A população desse estudo foi composta por 06 agentes comunitários de saúde lotados em uma UBSF que nos levantamentos realizados entre 2014 a 2016, obteve um número maior de afastamentos médico com CID do grupo F, que corresponde aos Transtornos Mentais e Comportamentais (CID.10)

Os critérios para seleção dos participantes foram: 1) ser agente comunitário de saúde; 2) possuir vínculo trabalhista com a FundaSUS; 3 ) Consentir em participar da pesquisa através da assinatura do Termo de Consentimento Livre e Esclarecido. Foram excluídos do estudo os ACS que não atenderam aos critérios anteriormente estabelecidos, bem como os que estavam de férias, ou licença de qualquer natureza.

\section{Instrumentos de Coleta de Dados}

Para a produção dos dados adotou-se um questionário e uma entrevista semiestruturada que permitiu identificar o perfil sócio demográfico e profissional e familiar dos ACS incluídos na pesquisa, abrangendo questões quanto ao sexo, idade, estado civil, escolaridade, número de filhos, tempo de trabalho e afastamento das atividades do trabalho. Trata-se de uma adaptação de dados solicitados pelo IBGE (2013) e informações contemporâneas construídas pelos pesquisadores visando a caracterização da população estudada.

Foi utilizada uma entrevista, norteada por um roteiro contendo tópicos em torno de uma problemática central cujo objetivo era descrever a organização dos processos de trabalho e identificar as situações geradoras de sofrimento no trabalho a partir da visão do agente comunitário de saúde. Estas entrevistas foram realizadas em ambiente reservado e silencioso da unidade de saúde, foram também gravadas em áudio para possibilitar as transcrições das mesmas e permitir as análises do material sem qualquer prejuízo. Após analise e transcrição das entrevistas, as gravações foram apagadas.

De acordo com Manzini (1991), a entrevista semiestruturada está focalizada em um assunto sobre o qual é preparado um roteiro com perguntas relevantes e complementada por outras questões inerentes às circunstâncias do momento da execução da entrevista. Para este autor a entrevista semiestruturada pode fazer emergir informações de forma mais livre e as respostas não estão condicionadas a uma padronização de alternativas.

Os dados foram coletados no mês de maio de 2018 após submissão e aprovação do projeto ao Comitê de Ética em pesquisa da Universidade Federal de Uberlândia em 06/03/2018, sob o CAAE № 80456817.6.0000.5152, utilizando o questionário e a entrevista semiestruturada supracitados. Ressalta-se que as seis entrevistas foram realizadas no local de trabalho dos participantes em sala privativa tendo em vista as particularidades dos conteúdos nas falas. Houve preocupação em deixar os pesquisandos à vontade para responder os questionamentos e esclarecer qualquer dúvida a respeito 
dos mesmos. No entanto, não foram percebidas dificuldades ou limitações por parte dos participantes do estudo.

\section{Observação participante}

Minayo (2007) define a observação participante como um processo pelo qual se mantém a presença do observador numa situação social com a finalidade de realizar uma investigação científica, na qual o observador está face a face com os observados. Ao participar da vida deles, no seu cenário cultural, colhe dados e se torna parte do contexto sob observação, ao mesmo tempo modificando e sendo modificado por este. No campo da saúde, enfatiza o ponto de que ele deve ser observado em relação com a realidade econômica, política e social mais ampla da qual faz parte. Para isso, é imprescindível considerar as classes sociais, as ideologias e visões de mundo dominante, além das especificidades do modo de produção influenciando tanto a organização dos sistemas de saúde como as estratégias que se estabelecem entre agrupamentos e classes sociais diante do fenômeno saúde e doença.

\section{Análise dos dados}

Os dados quantitativos coletados por meio do questionário socio demográfico e profissional foram analisados de forma descritiva. Os dados qualitativos foram submetidos a Análise de Conteúdo Temático e interpretados segundo o referencial teórico de sofrimento patogênico de Cristophe Dejours. A Análise de Conteúdo Temático foi desenvolvida em três etapas:

Pré-Análise: leitura flutuante do material transcrito norteada pelas hipóteses e pelos objetivos iniciais, seguida pela confecção de novas hipóteses, que junto às hipóteses iniciais e à teoria selecionada para a análise permitem a formação dos indicadores; Exploração do Material: visa alcançar o núcleo de compreensão do texto por meio da identificação das palavras e expressões mais significativas em torno das quais o conteúdo se organiza (categorias).

\section{O TRABALHO E A SAÚDE DO TRABALHADOR}

No trabalho é comum as pessoas apresentarem a depressão como resposta física ou psíquica das situações vividas. Podendo apresentar sentimentos ou intenções suscetíveis ao comprometimento das relações anteriormente estabelecidas naquele contexto, seja em razão de injustiças sofridas no local do trabalho, ou em decorrência de dificuldades pessoais graves, que atingem a esfera do trabalho produtivo (DEJOURS; BÈGUE, 2010).

Neste contexto há que se entender que os riscos e agravos à Saúde do Trabalhador derivam do processo de trabalho e de como este processo está organizado, articulados a uma série de relações, como o próprio cotidiano, o ambiente e as condições de trabalho, as relações com o tempo e o espaço os modos de se trabalhar, dentre outros. E segundo SATO (2002) é a partir desta organização que podem surgir as psicopatologias do trabalho.

Segundo Lacaz (2007), pensar o cenário da Saúde dos Trabalhadores compreende resgatar uma história que se inicia no final dos anos 70 , a partir de um campo do conhecimento cujas relações saúde/doença-trabalho situa-se dentro da Medicina Social Latino-americana, cuja corrente programática se coloca em interface com a Saúde Pública, a Medicina Social e a Saúde Coletiva, sendo diferenciada da Saúde Ocupacional e da Medicina do Trabalho, pensando, também, sobre as diversidades epidemiológicas dos agravos a saúde dos trabalhadores provocadas pela introdução das novas tecnologias e pela organização do trabalho.

A Lei Orgânica da Saúde, 8080/90, no Art. 6º, inciso 3ํ, define a saúde do trabalhador como:

[...] um conjunto de atividades que se destina, através das ações de vigilância epidemiológica e vigilância sanitária à promoção e proteção da saúde dos trabalhadores, assim como visa à recuperação e reabilitação da saúde dos trabalhadores submetidos aos riscos e agravos advindos das condições de trabalho [...] BRASIL, 2003, p. 24). 
A $3^{a}$ Conferência Nacional de Saúde do Trabalhador configura a "Saúde do Trabalhador" como algo ligado inteiramente à saúde, compreendida como parte e responsabilidade do SUS que, devido à área de ação de seu campo, é caracterizada como:

[...] intersetorial (envolvendo todos os níveis de atenção e esferas de governo do SUS) e intrasetorial (envolvendo setores relacionados com a Previdência Social, Trabalho, Meio Ambiente, Justiça, Educação e demais setores relacionados com as políticas de desenvolvimento), exigindo uma abordagem multiprofissional e interdisciplinar (saúde, engenharia, ciências humanas) e com a participação pró-ativa do trabalhador (BRASIL, 2005, p.4).

O Ministério da Saúde reconhece uma série de transtornos mentais, de personalidade e do comportamento relacionados ao trabalho, como por exemplo, delírio, transtornos cognitivos, estresse pós-traumático, neurose profissional, transtorno de vigília-sono, síndrome do esgotamento profissional (Burnout), síndrome do pânico, episódios depressivos e alcoolismo crônico. Porém, estudos sobre psicopatologia do trabalho mostram que o sofrimento no trabalho repercute não só na vida psíquica, ocorrendo assim uma desestruturação na saúde em todos os seus aspectos, como a doença mental e a doença somática (BRASIL, 2005).

Segundo a teoria de Dejours (2004), entende-se que o sofrimento patogênico do indivíduo surge quando a organização do trabalho entra em conflito com os desejos do sujeito, ou seja, com o funcionamento psíquico deste. E para se proteger criam-se as estratégias defensivas do homem, em relação ao ambiente. Patologia é o termo comumente utilizado, na literatura de Psicologia do Trabalho, para designar "descompensação psicopatológica, ou seja, uma ruptura do equilíbrio psíquico que se manifesta pela eclosão de uma doença mental" (DJOURS, 2006, p. 35).

Dejours (2004) já discutia um novo conceito de saúde considerando três elementos fundamentais para a saúde do trabalhador: 1) a fisiologia, ou seja, o funcionamento do corpo (análise do funcionamento do organismo, as regras que asseguram seu equilíbrio e sua sobrevivência), 2) a psicossomática (relações que existem entre o que se passa na cabeça das pessoas e 0 funcionamento de seus corpos) e por fim, 3) a psicopatologia do trabalho (adoecimento psíquico do ser humano, o que se denomina historicamente doença ou transtorno mental).

Os ACSs são o elo entre a equipe e a comunidade, a ponte entre o saber popular e o científico. Vivem sob contradições por vivenciar a realidade e as práticas de saúde dos bairros em que residem e trabalham (podendo gerar pressões e sobrecarga adicional), além da formação pelo referencial biomédico (SILVA; MENEZES, 2008). Pode-se constatar através de revisão de literatura que o ACS desenvolve várias atividades dentre as regulamentadas e outras além, sobressaindo a visita domiciliar e educação em saúde, mas que desempenham também atividades burocráticas na equipe, sendo respectivamente a mais apreciada e a menos apreciada por estes. $\mathrm{E}$ que, fatores como idade, nível de escolaridade e religião podem influenciar no modo de desempenhar estas (FERRAZ; AERTS, 2004).

As vulnerabilidades apontadas por Lima et al. (2011) para esses profissionais que atuam em várias situações ao mesmo tempo (doença/saúde; prevenção/assistência; educação/informação), com contato direto com a comunidade, que somadas a jornada e condições de trabalho, o deixa propenso a um sofrimento mental. Sob esse ponto de vista sentem-se responsáveis por sua comunidade e na medida em que percebem que não conseguem ser tão efetivos quanto gostariam, tornam-se vulneráveis a depressão e baixa-estima frente a determinadas situações.

De acordo com Lancman et al. (2009), podem sofrer a violência do trabalho (deterioração das condições de trabalho, com risco de acidentes e adoecimentos) e a violência no trabalho (relação com pares, chefia e o público no exercício de suas funções). Somando-se a esta dinâmica, os comportamentos abusivos, ameaças ou ataques com riscos para saúde, bem-estar e segurança, podendo ser interna, com algum grau de ligação com o local de trabalho; externa, quando não há ligação com o trabalhador, quando é praticada por algum usuário, com alguma relação profissional entre o trabalhador e o autor do ato violento e a violência indireta. Sendo assim, muitas vezes o trabalhador no desempenho de suas funções convive com situações de miséria, em que não dispõe de recursos para resolver e propor alternativas, levando a agir contra seus valores, vontade, violando a dignidade humana. O que pode ocorrer com frequência, pois trabalham em áreas de maior risco social, com consequente intensificação da violência. 
Laurell e Noriega (1989) colocam que compreender a relação entre saúde e doença coletiva como processo social é primordial para entender a saúde do trabalhador. Supõe que estudos sobre o processo saúde-doença têm de ir além da dimensão do indivíduo. Ainda segundo Laurell (1982), essa percepção presume uma crítica à explicação biológica da doença a fim de chegar a uma interpretação fundada em seu caráter social. Ela propõe, então, construir outro saber que ofereça mais possibilidades de abordar o problema da saúde associada com o trabalho como fenômeno coletivo e social; um saber que recorte uma prática que não só dependa de uma interpretação do processo saúde-doença, mas também se posicione fundada em bases sociais que a impulsionem e a ampare.

No Brasil, o campo Saúde do Trabalhador reflete a trajetória que deu origem a seu desdobramento e é marco de seu corpo conceitual e metodológico. Ainda que nem sempre essas premissas sejam claras, trata-se de meta, horizonte, de uma vontade que une trabalhadores, profissionais de serviços, técnicos e pesquisadores. Com efeito, as classes trabalhadoras formam um novo sujeito político e social segundo o campo Saúde do Trabalhador: o trabalhador sai da passividade, da posição de hospedeiro, paciente para aprender e se tornar um agente de mudanças que se vale de saberes relativo a seu trabalho e suas vivências partilhadas na coletividade para intervir e transformar a realidade laboral, atuar no controle da nocividade; na definição de prioridades de intervenção e na elaboração de estratégias transformadoras (LACAZ, 2007).

\section{OS AGENTES COMUNITÁRIOS DE SAÚDE}

A pesquisa foi realizada com os ACS de uma Unidade Básica da Saúde da Família, situada na região oeste da cidade. A UBSF tem três equipes e é referência para 10 mil pessoas aproximadamente (Quadro 1).

Quadro 1 - Profissionais que atuam Unidade de Saúde da Família em estudo

\begin{tabular}{|c|l|}
\hline & 1 Médico \\
& 1 Enfermeiro \\
& 1 Técnico de Enfermagem \\
& 2 ACS \\
& 3 Cirurgiões-Dentistas \\
& 2 Técnicos de Saúde Bucal \\
\hline & 1 Médico \\
& 1 Enfermeiro \\
& 1 Técnico de Enfermagem \\
& 4 ACS \\
\hline & 1 Cirurgião-dentista \\
& 1 Técnicos de Saúde Bucal \\
\hline & 1 Médico \\
& 1 Enfermeiro \\
& 1 Técnico de Enfermagem \\
& 3 ACS \\
\hline & 1 Cirurgião-dentista \\
& 1 Técnicos de Saúde Bucal \\
\hline & 2 Psicólogos \\
& 1 Nutricionista \\
& 1 Assistente Social \\
& 2 Educador Físico \\
& 1 Psiquiatra \\
\hline & 1 Ginecologista \\
& 1 Fisioterapeuta \\
\hline & 1 Fonoaudiólogo \\
\hline & 1 Gerente de Unidade de Saúde \\
& 2 Auxiliar Administrativo \\
\hline
\end{tabular}


A UBSF está estruturada com uma recepção, sala de espera, salas de atendimento (atendimento de enfermagem, atendimento médico, atendimento multiprofissional, atendimento de odontologia), sala de procedimentos, sala de reuniões, sala dos ACS, cozinha, banheiros e área externa (ampla).

A unidade abre às 7 hs e chegam os profissionais, que logo vão se dirigindo aos seus locais de trabalho para iniciarem a jornada. Enquanto isso também já chegam os usuários que vão se organizando para serem atendidos na ordem de chegada, ou para a coleta de sangue, ou para as consultas e/ou acolhimento, ou para os grupos operativos, e ou para quaisquer outras informações na recepção. Os usuários entregam os seus cartões e aguardam serem chamados para 0 atendimento. Os que vão participar dos grupos já se dirigem aos locais pré-determinados.

Os ACS chegam tomam café e logo começam suas atividades: auxiliam na coleta, organizam seu material, separam junto com os oficiais administrativos da recepção as consultas e ou exames que devem entregar naquele dia e planejam as visitas. Os que auxiliam na coleta de materiais para exames, recolhem os cartões e pedidos e os colocam em ordem de chegada, e fazem algumas orientações, tiram dúvidas dos usuários. Assim que terminam essa tarefa, organização seus materiais e saem para visitas. Os que auxiliam nos grupos, permanecem na unidade no turno da manhã, e logo que encerram os grupos, vão para a sala dos ACS e fazem os lançamentos das atividades realizadas. São liberados para o almoço às 11:00hs, a maioria almoça em casa retornando às $13 \mathrm{hs}$.

Após o almoço verificam as atividades que deverão realizar no período da tarde, e saem para as visitas, retornando até as $16 \mathrm{~h} 30 \mathrm{~min}$, quando chegam na unidade para fazer suas necessidades fisiológicas, beber água e fazer um breve lanche, finalizando as atividades do dia. Alguns ACS dependendo a necessidade solicitam nos locais externo (casa ou comercio) para utilizarem o banheiro.

Durante as atividades junto aos grupos operativos, trabalham como apoio ao profissional que coordena o grupo, fazendo anotações do mapa de grupos e organizando o material utilizado naquela atividade. Também pontuam algumas situações que já conhecem do paciente para que possam ser resolvidas prontamente. Durante e após o trabalho com grupo, agendam consultas na unidade, confirmam as receitas para atualização junto ao médico, dentre outros. Na coleta de materiais para exames, o ACS verifica o cartão da unidade, o pedido de exame e os organizam para o atendimento. A maioria das vezes no período da manhã, inicialmente fazem lançamentos de informações no computador e após saem para visitas.

Nas visitas, previamente verificam o que tem para ser entregue em sua área de responsabilidade: consultas, receitas, etc. Também, confirmam visitas compartilhadas com Assistente Social e ou enfermeira, e ou médica. Durante as visitas, os ACS que já são conhecidos em sua área, são recebidos cordialmente e numa conversa breve, levantam necessidades ou informam resultados de solicitações anteriores. Gastam em média 15 a 20min nas visitas.

Nas visitas compartilhadas, os ACS são apoiadores, pouco se manifestam, tendo os demais profissionais uma atuação maior tanto para orientações como intervenção junto ao paciente, que geralmente está acamado ou sem condições naquele momento de qualquer ação. Nestas visitas 0 tempo médio é de até 30min dependendo a intervenção a ser feita. Geralmente o profissional A.S, médico, psicólogo, ou enfermeiro agendam uma visita compartilhada, pois o deslocamento demanda tempo e não há veículo para esta locomoção, se for próximo a unidade, vão a pé, mas geralmente utilizam seus veículos próprios devido a distância, já que não tem veículo disponível para tal.

Foi observado durante as visitas que em todas as situações os profissionais da unidade são bem recebidos, há uma expectativa quanto a resolução do problema apresentado de imediato, que seja o curativo a ser feito, a entrega do agendamento de consulta, ou orientação e verificação da condição de saúde daquele paciente naquele momento.

Na unidade, o tempo do ACS é utilizado para as atividades administrativas, quando tem que fazer os lançamentos de sua produtividade, atualização dos dados cadastrais, cadastramento de novas famílias, etc. Foi observado que as atividades administrativas ocorrem na maioria das vezes no período da manhã, destinando o período da tarde para o trabalho em campo. Quanto a interação entre os profissionais da unidade não foi observada nenhum clima em que pudesse gerar conflitos. A relação entre todos foi cordial e de ajuda mútua. 
Nas quintas feiras á tarde, acontecem as reuniões de equipe, onde são colocadas as situações de destaque que aconteceram durante a semana, ou que foram resolvidas ou que estão pendentes de resolução, bem como passar informes gerais.

$\mathrm{Na}$ UBSF são ofertados à população consultas médicas, de enfermagem, agendamento de exames, vacinas, curativos, nebulização, administração de medicações básicas, lavagem de ouvido, aferição da pressão arterial e controle da glicemia capilar, atendimento em demanda programada do SISPrenatal e HiperDia, visitas domiciliares, grupo de educação em saúde, acompanhamento de pacientes com tuberculose e hanseníase nos casos previstos para atenção básica e muitos outros serviços.

Para receber $\mathrm{o}$ atendimento na Atenção Básica os indivíduos e as famílias precisam estar cadastrados e residir na área de abrangência da unidade. Esse cadastro é realizado por meio da visita domiciliar do agente comunitário de saúde ou pessoalmente nas Unidades Básicas de Saúde da Família. Participaram do estudo seis ACS, sendo quatro mulheres $(66,67 \%)$ e dois homens. A predominância feminina propicia uma reflexão a partir de Dejours (2004) quando destaca que o trabalho feminino apresenta um caráter paradoxal, por um lado faz a mediação das relações de dominação dos homens sobre as mulheres, mas por outro é um instrumento de reapropriação dos direitos das mulheres, o que representa um meio de conquista de novas normas de vida e, consequentemente, de saúde (Tabela 1).

Tabela 1: Características sociodemográficas dos agentes comunitários de saúde $(n=6)$

\begin{tabular}{|c|c|c|}
\hline VARIÁVEIS & $\mathbf{N}$ & $\%$ \\
\hline \multicolumn{3}{|l|}{ Idade (Anos) } \\
\hline $18-29$ & 2 & 33,3 \\
\hline $30-39$ & 1 & 16,7 \\
\hline $40-49$ & 2 & 33,3 \\
\hline $50-59$ & 1 & 16,7 \\
\hline 60 ou mais & 0 & 0,00 \\
\hline \multicolumn{3}{|l|}{ Estado Civil } \\
\hline Solteiro & 3 & 50,00 \\
\hline Casado & 2 & 33,33 \\
\hline Viúvo & 1 & 16,67 \\
\hline
\end{tabular}

\section{Grau de Escolaridade}

\begin{tabular}{|l|c|c|}
\hline Superior completo & 0 & 0,00 \\
\hline Superior incompleto & 4 & 66,67 \\
\hline Ensino Médio completo & 2 & 33,33 \\
\hline Ensino Médio incompleto & 0 & 0,00 \\
\hline
\end{tabular}

Tempo de Atuação como ACS (meses)

\begin{tabular}{|l|c|c|}
\hline 1 a 12 & 0 & 0,00 \\
\hline 13 a 24 & 1 & 16,67 \\
\hline 25 a 36 & 3 & 50,00 \\
\hline 37 a 48 & 2 & 33,33 \\
\hline
\end{tabular}

Estudos desenvolvidos com ACS em outros municípios brasileiros apresentaram resultados semelhantes a este, isto é, a predominância do trabalho feminino (MARTINS et al., 1996; ANDRADE, 1998; SILVA \& DALMASO, 2002; FERRAZ \& AERTZ, 2005; SANTOS et al., 2006; AZAMBUJA et al., 2007).

Ressalta-se que estas pesquisas foram realizadas em períodos diferentes e que não existe mudança neste aspecto ao longo dos anos. Essa tendência também é observada entre os profissionais da saúde. Assim, destaca-se que as relações de gênero perpassam o mundo do trabalho 
e a divisão sexual, evidenciando as formas pela qual a sociedade organiza a produção e a reprodução (BRITO, 2005).

Com idades entre 26 e 51 anos, os ACS deste estudo atendem a um dos pré-requisitos estabelecidos pelo Ministério da Saúde para ser ACS que é ter idade acima de 18 anos (BRASIL, 2001), isto é, deve possuir capacidade civil plena, não existindo determinação de limite máximo de idade.

O predomínio de adultos jovens (20 a 40), observado em outros estudos, como os realizados por Andrade (1998), Silva e Dalmaso (2002) e Santos et al. (2006), não foi observado por este estudo. Foi constatada que apenas metade dos entrevistados era considerada adultos jovens, mas a outra metade dos entrevistados estava além desta faixa etária. Coerentemente com essa diversidade de idades, pesquisas revelaram que, para muitos ACS, o trabalho na Estratégia Saúde da Família foi uma oportunidade de reingresso no mercado e, para outros, representou reconhecimento e remuneração do trabalho já desenvolvido na comunidade (SILVA; DALMASO, 2002).

Com relação ao estado civil, 3 são solteiros (50,0\%), 2 casados (33,3\%) e 1 viúvo (16,7). Esses dados são consistentes com os encontrados por Assunção (2003), também corroboram os estudos de Lino et al. (2012) que em sua maioria os ACS são do sexo feminino e casadas, com um ou dois filhos dependentes, demonstrando que a mulher contemporânea além de ter um emprego que auxilia na renda familiar, também desenvolve atividades domésticas em sua própria residência, cuida dos filhos e do marido, restando pouco tempo para o cuidado de si.

Quanto a formação, 66,67\% dos entrevistados relataram possuir ensino superior incompleto, o que vai além do estabelecido pela Lei n. 11.350/2006. Esse achado corrobora outros estudos (BERNARDES, 2008; VASCONCELOS; COSTA-VAL, 2008; KLUTHCOVKY, 2005).

De acordo com Ferraz e Aerts (2005), quanto mais anos de estudos o ACS tem, mais condições ele terá de aprender e orientar as famílias. Percebe-se que os ACSs deste estudo informaram estarem realizando cursos na área de humanas (Serviço Social, Recursos Humanos, Educação Física e Administração) o que mais se aproxima de seu campo de atuação, buscando uma identificação, o que é confirmado pelos estudos de Silva e Dalmaso (2002). Por outro lado, para Reis (2005), a estratégia de superação das dificuldades cotidianas do trabalho foi a mudança de profissão em que o ACS faz o curso técnico-profissionalizante a fim de obter o reconhecimento social e a valorização salarial.

No tocante ao tempo de atuação como ACS, (50\%) trabalham entre 25 a 36 meses. Esse resultado se assemelha ao estudo de Almeida at.al (2016) que investigou cargas de trabalho e processo de desgastes em ACS onde predominou tempo de trabalho menor que 3 anos, demostrando alta rotatividade, podendo ser considerado um fator que impossibilita 0 desenvolvimento do vínculo com as famílias e a comunidade interferindo no trabalho (GALAVOTE et al.; 2011; MOTA, 2014).

Segundo os estudos de Carvalho (2002) além da falta de oportunidade, trabalhar como ACS surge como uma possibilidade de melhoria das condições de trabalho por meio da mudança de emprego, de busca por outra área de atuação, ou procura do crescimento profissional, mesmo desconhecendo as atividades que desenvolveria.

Em relação aos afastamentos médicos nos últimos doze (12) meses, os entrevistados informaram: nenhum afastamento (1); um afastamento (1); os demais dois ou três afastamentos. A análise das entrevistas permitiu a formação de quatro temas: a) Cotidiano de Trabalho dos ACS; b) Fontes de Prazer no Trabalho, c) Frustrações diante da incapacidade de resolver os problemas; d) Questões que interferem no processo de trabalho.

\section{O cotidiano de trabalho dos ACS}

As entrevistas confirmaram que o trabalho do ACS é focado principalmente nas visitas domiciliares, momento em que são realizadas diversas atividades: os cadastramentos familiar e individual, a prevenção da dengue e outras endemias, as visitas compartilhadas e a busca ativa. Para Ávila (2011), são inúmeras as atribuições sob a responsabilidade dos ACS no trabalho na 
comunidade, uma vez que muito se é exigido das Equipes de Saúde da Família, tanto na visão da integralidade do cuidado (da promoção a reabilitação), mas também pela ampla gama de doenças que são prevenidas e acompanhada pelos profissionais da Atenção Primária.

A gente faz visitas domiciliares, faço cadastro, né e traz a demanda da população para o postinho para tá agilizando; é uma pessoa acamada que precisa de visita; é uma pessoa que está com exame meio atrasado que precisa agilizar (Entrevista 1).

Nós visitamos, a gente faz prevenção do mosquito da dengue, e faz visita domiciliar, pra ver pessoa idosa, que tá acamado, a gente visita familiar, além da visita a família, a gente faz o controle de endemias. Na visita domiciliar o controle de endemias (Entrevista 2).

As atividades são várias, visitas domiciliares, hoje nós estamos fazendo um trabalho de orientação, prevenção e controle de zoonoses, visitas compartilhadas com equipe multiprofissional, a gente dá prioridade para visitas três vezes por mês, gestantes, hipertensos, diabéticos e as crianças. (Entrevista 5).

Nos relatos apresentados, foi possível perceber que a visita domiciliar é um instrumento essencial na prática das ações no nível primário de assistência à saúde principalmente na Estratégia Saúde da Família, constituindo um elemento que facilita o acesso por parte dos usuários aos serviços públicos de saúde e assim, identificar as reais necessidades de cada indivíduo e família. Coerentemente a esse resultado, o trabalho de Machado et al. (2015) que teve como objetivo conhecer a percepção do ACS na sua atuação profissional, constatou que as visitas domiciliares, a propagação de informações e orientações aos usuários foram consideradas pelos ACS como atividades prioritárias do seu trabalho na ESF. Sendo a visita domiciliar ao mesmo tempo educativa e assistencial se torna um espaço importante das práticas de cuidado amplo aos usuários e a comunidade onde o ACS tem a oportunidade de visitar e acompanhar tanto as pessoas saudáveis quanto as doentes de sua micro área. (Kebian et al. 2011).

Outro ponto importante observado nas falas dos entrevistados é a participação de outros profissionais da equipe no atendimento aos usuários do serviço. No estudo de Santos et al. (2011), que investigou a percepção dos enfermeiros quanto a visita domiciliar na Estratégia Saúde da Família, verificou-se que a VD tem sido considerada o diferencial por parte dos trabalhadores que constituem a ESF. Ainda para este autor, vale ressaltar que durante a realização da VD, se os profissionais de saúde e usuários estabelecerem uma relação onde reconheçam os diferentes saberes e entre si complementem suas ações fortalecendo o vínculo, será mais fácil de ocorrer o desenvolvimento da assistência de forma integral.

Observamos que apesar de toda cobrança, os agentes conseguem criar estratégias de resistência quanto a forma da organização do trabalho, no que tange ao número de atividades que lhe são atribuídas. É na visita domiciliar que realizam as demais atividades, tais como a entrega de encaminhamento a consultas, receitas prescritas, e outras orientações, adequando as visitas ao resultado esperado de produtividade. Diante disto pode-se afirmar que o serviço só funciona "[...] quando os trabalhadores, por conta própria, usam artimanhas, macetes, quebra-galhos, truques; quando antecipam, sem que Ihes tenham explicitamente ordenado, a incidentes de toda sorte" (DEJOURS, 2003, p. 56).

Outro resultado percebido nas falas dos entrevistados foi a insatisfação inicial da inclusão da atribuição quanto ao controle de endemias, também chamado de "trabalho da zoonoses" ou prevenção da dengue pelos ACS, destacado nas verbalizações abaixo:

"A gente faz as visitas domiciliares, que é todos os dias, a gente passa nas casas uma vez por mês em todos os nossos pacientes, uma vez mês; agora também a gente faz o trabalho da zoonoses, mesmo serviço do pessoal, que é orientação e prevenção, a gente olha o quintal(dengue) preenche a fichinha 201; a gente faz busca ativa, faz grupos aqui na unidade, faz visitas domiciliares com as médicas, e é basicamente isto no dia a dia" (Entrevista 4).

"A gente faz a visita domiciliar e junto faz as orientações de zoonoses (dengue). A inclusão da zoonoses não é a mesma coisa, pois a zoonoses tem uma cobrança muito grande em questão de quantitativo, números. Trabalhamos muito com números. Antes da zoonoses vir, a gente trabalhava por rua, nós fazia 
visitas por rua. Hoje a gente não faz mais isto, por causa da zoonoses a gente tem que trabalhar por quarteirão. Hoje a gente já é mestre nisto. No começo foi muito difícil, a gente acostumar com serviço de quarteirão" (Entrevista 5).

Apesar da atividade de controle de endemias se constituir como um trabalho já incorporado, é resultado de um processo que inicialmente representou um desafio para esses profissionais. Vale ressaltar que os ACS e o ACE são corresponsáveis pelo controle da dengue e trabalham de forma integrada e complementar. Muitas das ações desenvolvidas são comuns aos dois profissionais, como a educação em saúde, mobilização comunitária,

identificação de criadouros, entre outras. Entretanto, algumas ações são específicas ao ACS, como a identificação das pessoas doentes e busca ativa de casos novos, enquanto outras são específicas do ACE, como a destruição de criadouros de difícil acesso ou utilização de inseticida. (PNAB, 2017).

De fato, o trabalho do ACS é compreendido em três grandes grupos de ações, a saber: 1) promoção e prevenção da saúde; 2) mediação entre a Unidade de Saúde e os usuários; e 3) acompanhamento e reabilitação dos usuários (ÁVILA, 2011). Dessa forma, observa-se que o trabalho com a prevenção e controle da dengue, como abordado anteriormente, tem encontrado espaço junto às demais ações consideradas prioritárias para o ACS: o acompanhamento e vinculação entre Unidade de Saúde e população adstrita. Com relação às atividades de controle e prevenção da dengue, a Portaria n. 44/2002 define as atribuições dos ACS, considerando a importância de sua atuação na sua prevenção e controle (BRASIL, 2002). Corroboram também os estudos de Santos et al (2010) quando apontam que as ações de competência de Prevenção e Monitoramento de Riscos Ambientais e Sanitários integram as atribuições do ACS.

O estudo de Silva et al (2012) confirma as fragilidades no reconhecimento pelos ACS quanto as suas atribuições, que consistem em atividades básicas: visita domiciliar, educação em saúde e o controle e prevenção da dengue, além de outras que lhe são alheias, tais como a entrega de receitas, medicamentos e encaminhamentos médicos em domicílio e o exercício de atividades administrativas na UBSF.

Foi interessante notar ainda, o importante papel que o ACS desenvolve sendo vínculo entre a comunidade e os profissionais de nível superior. O processo de trabalho das ESF é caracterizado dentre outros fatores pelo trabalho interdisciplinar e em equipe, pela valorização dos diversos saberes e prática na perspectiva de uma abordagem integral e resolutiva (BRASIL,2006). Tal observação citada no relato abaixo, o entrevistado propicia o entendimento da discussão de casos e problemas como uma atividade realizada em equipe.

Quando a gente chega assim, no paciente e vê que ela tá necessitado pra ontem, a gente leva o Assistente Social, então sabe, porque tem os meios e consegue as vezes agilizar alguma coisa, mas não é sempre, mas ela tem conseguido resolver alguma coisa (Entrevista 1).

Então, esses pacientes que moram sozinho, que não tem condições de vir aqui, às vezes são cadeirante, domiciliado, a gente leva a medica lá frequentemente, as visitas dela é toda sexta feira, ai nesses ela tem uma pasta na sala dela com todos os pacientes domiciliados, cadeirantes, com AVC, que já deu infarto, diabetes, hipertenso, gestante, todos de risco alto que a gente visita eles com mais frequência. Troca receita. Faz de três a quatro visitas, são programados. Com os outros profissionais é em outros dias (Entrevista 4).

Almeida (2009) corrobora com seus estudos que os desafios cotidianos na ESF, vem demonstrando um acúmulo de demandas de atenção a saúde da população adstrita, muitas vezes poderiam ser atendidas por profissionais especialistas. Resultados confirmados com da criação dos Núcleos de Apoio a Saúde da Família (NASF) mediante a portaria GM oo 154 de 24/01/2008 com objetivo de apoiar a inserção da Estratégia Saúde da Família na rede de serviços, de ampliar a abrangência e o alvo das ações da APS, como também aumentar a resolutividade dela, reforçando os processos de territorialização e regionalização em saúde BRASIL, 2009).

A seguir foram evidenciadas nas falas dos entrevistados outras atividades que podem ser consideradas como administrativas e que não estão incluídas nas funções dos ACS as quais eles não consideram como de sua competência. 
Eu auxilio na coleta de sangue todos os dias, a menina do checkup; faço visitas domiciliares; faço orientação de prevenção de combate a dengue; faço visitas com a médica, assistente social, psicólogo, nutricionista, estas são algumas atividades e faço busca ativa também na área do PSF (Entrevista 3).

Desde busca ativa na área atrás de crianças, gestantes, idosos, acamados e domiciliados, atividades administrativas dentro da própria unidade, "tapa buraco" na falta de outros profissionais, atividades sociorrecreativas dentro da própria unidade e entre mais outras coisas em relação da própria unidade em si (Entrevista 6).

Em estudos realizados anteriormente, por Vasconcelos (1997), verificou-se que o trabalho de suporte que o agente vem prestando às equipes de saúde sinaliza que, além de ser sobrecarregado com tarefas de sua atribuição, passa a ser um "tapa-buraco" da carência de outros profissionais nos serviços de saúde. Sendo assim, o ACS considerado polivalente, realiza várias funções além das preconizadas pelo Ministério da Saúde. Esta realidade permanece na atualidade, conforme constatamos nas falas acima. Estudos recentes de Queirós e Lima (2012), também confirmaram através de sua pesquisa sobre a institucionalização do trabalho do ACS, que este tem sofrido modificações pela ordem dominante "através dos desvios de função, como marcação de consulta, recepção, entre outras atividades". A literatura aponta, porém, que esse agente desenvolve em seu cotidiano de trabalho, algumas atividades que não são preconizadas pelo Ministério da Saúde, descaracterizando seu papel.

Quanto ao papel de mobilização o ACS fica em situação em que não tem como propor nada junto a população, uma vez que pouco tem a oferecer: as consultas especializadas e exames entram em fila de espera, medicação em falta, dentre outras situações em que fogem de suas alçadas. Se fizerem mobilização seria como um levante contra o próprio sistema buscando melhorias, o que entra em contradição com sua própria condição de trabalhador. Assim, entre essas nuances 0 ACS vive a dicotomia de estar a serviço de uma população, cujos recursos são escassos e sem condições de oferecer algo que realmente faça a mudança na vida destas pessoas. Dessa forma, é questionável se o ACS poderia estar livre dos conflitos que fazem parte de sua vivência pessoal e no trabalho.

O trabalho prescrito perpassa pela questão filosófica, longe da realidade com a qual ter que lidar duplamente: a sua própria e a dos usuários aos faz atendimento, evidenciando a distância com o mundo real, e que assim sendo propicia ao sofrimento patológico

\section{O sofrimento e o prazer do ACS no cotidiano de trabalho}

Quanto à fonte de prazer dos ACS ficou bem evidente que quando o seu trabalho é resolutivo, isso gera satisfação e prazer. Esse resultado, observado a partir das falas a seguir, aproxima-se ao conceito de ressonância simbólica, apontado por Dejours (2011). Para o autor, a ressonância simbólica ocorre quando há compatibilização a realidade de trabalho e as representações simbólicas.

Ah! Quando eu consigo resolver as demandas, aí eu fico tranquilo, quando o povo vem com as demandas, a gente traz e resolve eu fico tranquila (Entrevista $1)$.

O que realmente fico mais feliz é quando a gente consegue fazer uma interferência que cria um resultado, principalmente que nós temos muitos acamados, quando a fisioterapeuta vai lá, que aquela pessoa consegue uma melhoria no seu quadro ou a médica vai, solicita exames, volta lá prescreve medicamento e no retorno a gente vê que aquela pessoa, ele teve uma melhora no quadro. Isso é bom porque o que eu vejo de mais interessante neste trabalho do agente (Entrevista 3).

É a resolutividade dos problemas, porque o ACS, ele é a porta de entrada da unidade, então a maioria das pessoas que chegam na unidade a primeira vez é através da gente. Então assim o vínculo familiar quem conhece, quem sabe o que a família tem, o que ela precisa, é a gente. Então quando tem uma resolutividade o paciente fica satisfeito, tudo bom, eu gosto (Entrevista 5). 
Lopes et al. (2012) corrobora que ser resolutivo é identificado como aspecto positivo relacionado ao trabalho dos ACS, cuja característica é ligada ao sentimento de gratificação e utilidade, o que contribui para a satisfação profissional destes trabalhadores. Outra fonte de prazer percebida é quando há um reconhecimento por parte da comunidade do trabalho desenvolvido pelo ACS. Esse reconhecimento por parte da comunidade e a aceitação do outro são elementos fundamentais no processo de enfrentamento das adversidades do trabalho.

Nos estudos realizados por Alonso et al. (2018) quanto aos aspectos positivos analisados, apontaram que vários autores demonstraram a satisfação do ACS quanto ao seu trabalhado quando percebem o feedback positivo da comunidade e que constatam mudança nas condições de saúde dos usuários e consequentemente o reconhecimento de seu trabalho. Ainda em sua análise aponta outros estudos que reforçaram que estes achados são fatores de motivação dos ACS, fortalecendo a autoestima e contribuindo para conformação da identidade deste trabalhador.

A carinha dos pacientes porque quando, principalmente dos idosos, eles precisam muito da gente, então quando a gente chega, pode trocar uma receita, que a gente vem e marca uma consulta com médico ou leva o médico, além dele ficar feliz, a família também fica feliz. Então isso é gratificante, entendeu? A gente pega um vínculo muito grande com o paciente (Entrevista 2).

É poder ajudar o próximo, assim as vezes com pouca coisa, uma visita que você passa lá na casa da pessoa, ela já fica satisfeita, as vezes quer desabafar, as vezes você vai levar uma consulta já ajuda, então assim, você vê que é gratificante, principalmente os idosos. (Entrevista 4).

Para Dejours (2011), o trabalho é uma busca por reconhecimento, ou seja, pelo trabalho os seres humanos buscam uma valorização e criam expectativas de sucesso e gratidão. O reconhecimento no trabalho é um elemento indispensável para a proteção da saúde mental do trabalhador. Ainda para este autor, quando não há o reconhecimento, a organização do trabalho pode afetar a saúde mental. O reconhecimento possui um sentido duplo: o sentido de admitir a contribuição do trabalhador e o sentido de gratidão (DEJOURS, 1999).

Não há dúvidas de que o trabalho é uma relação social, histórica e intersubjetiva onde este se realiza para dar significado na vida do trabalho. Para Mendes (2007) o reconhecimento é o processo de valorização do esforço e do sofrimento investido para a realização do trabalho.

\section{Frustrações diante da incapacidade de resolver os problemas}

Quando questionados sobre situações que geram sofrimento no trabalho os entrevistados apontaram a impotência e a incapacidade em apoiar satisfatoriamente a comunidade por eles assistida, o que lhes causa frustração, como pode ser percebido pelas falas a seguir.

Olha, quando a gente escuta do idoso que ele está sendo maltratado pela família, aí é chato, é ruim a gente ouvir isto porque a pessoa que já está idosa está acamada, aquela pessoa, que membro da família que teria por zelar, cuidar da integridade e bem estar dele, a gente escuta que aquela pessoa está sendo até agressiva mesmo, a gente não tem muito que fazer, porque se traz para a assistente social ou psicóloga, alguém da família vai lá, nós na condição de agente de saúde obviamente vai ter as portas fechadas pelo agressor, isso é uma coisa que eu não gosto (Entrevista 3).

Então, assim, a gente lida com isso diariamente, porque às vezes o paciente esta ali precisando de uma ajuda, não depende de mim que passo lá, depende do superior, do enfermeiro, do médico, e assim é complicado porque tem toda uma hierarquia, às vezes a gente não fala, mas eu não posso, às vezes a gente passa o caso pra frente, às vezes você vê uma pessoa precisando de uma ajuda (Entrevista 4).

O que me deixa muito chateada é quando a gente se depara com casos de maus tratos, eu fico muito chateada, me abala, me envolvo emocionalmente, fico ruim, nestes casos, que não são poucos, tem bastante se depara muito com este tipo de coisa, então fico muito chateada. Eu tento fazer o que a gente fica muito limitado, nestes casos, a gente tem muita limitação (...). Você não tem o que fazer. 
Muitas vezes a gente sabe, a gente vê e não pode fazer nada. Isso eu fico muito chateada, me causa muito sofrimento (Entrevista 5).

De acordo com Ávila (2011), no processo de acompanhamento das famílias, descrito como atribuição do ACS é preciso estar atento ao que é exigido desse profissional. Por vezes ao ACS são atribuídas atividades cujos conhecimentos detidos por ele, são insuficientes para a solução dos problemas vivenciados na prática. Cabe pontuar que esses conhecimentos insuficientes do ACS permeiam tanto os conhecimentos em saúde humana, mas também de práticas pedagógicas e educativas.

É preciso resguardar que o sentimento de proximidade e incapacidade de atender às demandas da comunidade é inerente ao trabalho, o qual é essencialmente humano. Sendo humano, e não apenas uma instância qualquer do maquinário, o trabalho exige do trabalhador a mobilização da inteligência e da personalidade. Nesse processo, o trabalho que é prescrito não é realizado em sua integra, mas resulta do engajamento da criatividade e da ação moral o objeto de trabalho (DEJOURS, 2011).

Ainda em relação a ligação dos ACS com as famílias por ele assistidas, o prazer no trabalho é intensificado quando há ligação afetiva com o trabalho, ou seja, laborar naquilo o que gosta, o que o torna o trabalho fonte de sublimação (MENEZES, 2012).

Foi notória, ainda, a incapacidade do ACS em mobilizar a comunidade para a luta por melhorias na atenção em saúde. Essa incapacidade decorre tanto da ausência de suporte para a efetivação das demandas por ele encontradas, quanto da inexistência de ferramentas para estimular a comunidade. Há, portanto, um engessamento do profissional que assume a maior capilaridade do sistema de saúde, o qual não consegue tornar visível as carências de atenção em saúde observadas no cotidiano de trabalho.

Por outro lado, parece que o ACS, mesmo morando na comunidade onde executa as suas ações laborais, ao encerrar a sua jornada de trabalho esse profissional se desnuda das suas funções em prol da comunidade, não havendo ligação entre o seu trabalho e a comunidade onde vive. Apesar de ser observada essa desvinculação do ACS trabalhador e do ACS morador, não foi possível identificar as causas dessa descontinuidade.

\section{Questões que interferem no processo de trabalho}

Quando o ACS está diante da possibilidade de entrar em sofrimento diante a sua incapacidade de lidar com os problemas encontrados na comunidade, o mesmo cria estratégias de defesa que, como pode ser observado nas falas abaixo, são pautadas na culpabilização de outro ator, por vezes inalcançável, como a hierarquia, o sistema eletrônico ou a falta de materiais. Essa ocorrência se alinha com o pensamento de Dejours (2011), o qual afirma que os seres humanos, diante do sofrimento, elaboram estratégias de defesa, que nada mais são que a negação do domínio técnico do trabalho.

O que é oferecido no geral pelo postinho é as marcações de exames mais complexos que não marca aqui, a gente fala e as meninas lançam no sistema e marca na Central, ai isso demora, o povo reclama, isso é o maior empecilho. $\mathrm{A}$ pessoa fala, eu tô precisando de ortopedista, cardiologista, de um eletro, não sei o quê. E demora e a gente tem que falar espera, aí é meio difícil (Entrevista 1).

Porque os cadastros que a gente faz na rua, das novas famílias, a gente precisa colocar todo no sistema para poder funcionar (...). Então a gente faz manualmente na rua, chega aqui você tem que inserir no sistema, e o sistema não funciona. Aí te atrasa, as vezes o paciente está precisando de uma consulta, precisando fazer alguma coisa urgente, e não está inserido no sistema, não tem como atender. Isso dificulta. (Entrevista 5).

(...) nós fazemos o possível com o que temos, o máximo que a gente tem de material, coisas que temos que resolver para os pacientes a gente dá o melhor suporte possível com o que temos. Falta muita coisa? Falta. Vai faltar, mas no momento com o que temos, temos que conseguir o máximo possível (Entrevista $6)$. 
É notório, assim, que os ACS não estão inertes diante de momentos causadores de sofrimento, criando estratégias de defesa que aportam na culpabilização de um agente externo pela não realização das ações de cuidado e acompanhamento esperadas dele no desenvolvimento do trabalho. De fato, os trabalhadores não estão passivos diante da organização do trabalho, mas conseguem resguardar sua saúde mental e encontrar saídas para se "adaptarem às situações concretas" do trabalho (CANGUILHEM, 2002).

No pensamento de Dejours (1993) os sofrimentos insuspeitos não se apresentam de uma maneira única; eles estão associados a fatores históricos, laborativos e àqueles favoráveis ou não para a vida do trabalhador, relacionados à própria vida humana e ao trabalho. Ele os discrimina como: a) sofrimento singular (dimensão diacrônica): é herdado da história psíquica de cada indivíduo; b) sofrimento atual (dimensão sincrônica): ocorre quando há o reencontro do sujeito com o trabalho; c) sofrimento criativo: quando o sujeito produz soluções favoráveis para sua vida, especialmente, para sua saúde; e d) sofrimento patogênico: é ao contrário do sofrimento criativo, ou seja, quando o indivíduo produz soluções desfavoráveis para sua vida e que estão relacionados à sua saúde.

Na nova dinâmica da Psicopatologia do Trabalho, a normalidade é considerada um enigma, pois, a maioria dos trabalhadores não consegue preservar um equilíbrio psíquico e manter-se na normalidade, a exceção passou a ser a regra, ou seja, a regra hoje é o sofrimento e não a normalidade. Com essa constatação, as investigações na área da Psicopatologia do Trabalho centram-se, não mais na direção das doenças mentais, mas, nas estratégias elaboradas pelos trabalhadores para enfrentarem, mentalmente, a situação de trabalho. A partir desse novo paradigma, Dejours (1994) define a normalidade como o equilíbrio psíquico entre constrangimento do trabalho desestabilizante ou patogênico e defesas psíquicas.

O equilíbrio seria o resultado de uma regulação que requer estratégias defensivas especiais, elaboradas pelos próprios trabalhadores; porém, a normalidade conquistada e conservada pela força é trespassada pelo sofrimento (DEJOURS, 1994). Ainda de acordo com esse autor, as relações de trabalho, dentro das organizações, frequentemente, despojam o trabalhador de sua subjetividade, excluindo o sujeito e fazendo do homem uma vítima do seu trabalho (DEJOURS, 1998).

\section{CONSIDERAÇÕES FINAIS}

Esta pesquisa se propôs a compreender como o sofrimento patogênico de ACS se relaciona a organização do processo de trabalho em uma unidade da ESF; em decorrência isto se buscou delinear o perfil sócio demográfico dos ACS participantes, analisar a organização do processo produtivo procurando investigar possíveis aspectos que influenciam o processo saúde-doença dos ACS da UBSF em questão, em especial as possíveis situações geradoras de sofrimento patogênico. Para tanto, procurou-se estabelecer um diálogo na interface da saúde do trabalhador com a saúde mental, salientando as relações entre trabalho, saúde e subjetividade.

A metodologia utilizada foi suficiente para produzir resultados satisfatórios que ajudaram a responder à questão proposta pela pesquisa. Com uma abordagem qualitativa este estudo foi conduzido por meio da observação participante e entrevistas individuais semiestruturadas com agentes comunitários de saúde da Estratégia Saúde da Família. O material selecionado foi submetido à análise de conteúdo temático e interpretado segundo o referencial teórico de Christophe Dejour sobre sofrimento patogênico relacionado ao cotidiano de trabalho dos ACS, pelo qual se buscava entender pela fala dos entrevistados e pela observação participante, as fontes de prazer no trabalho e suas frustrações mediante a incapacidade de responder às demandas apresentadas.

A presente pesquisa confirmou os achados em outros estudos quando demonstrou o predomínio das mulheres casadas com idade, entre 20 e 40 anos no exercício desta profissão. E também vale ressaltar que quanto a escolaridade houve avanços, apontando que o ACS hoje superou este requisito, estando em sua maioria cursando ensino superior. Fato que leva a reflexão quanto a busca deste profissional por uma melhoria na sua condição de trabalho, tanto na expectativa financeira, quanto do conhecimento. Isto nos deixa antever que estes ACS podem em breve deixar a função, buscando uma ocupação profissional de maior valorização profissional e financeira. 
Com relação ao ambiente de trabalho conclui-se que a estrutura física da unidade de saúde atende aos requisitos fundamentais para a realização do trabalho do ACS, quando observamos que os profissionais que ali desempenham suas atividades têm os recursos mínimos necessários (sala de trabalho, computadores, etc.).

Quanto à organização do trabalho, observou-se a discrepância entre o trabalho prescrito e 0 trabalho real que os ACS realizam. Constatou-se que algumas atividades realizadas pelos ACS não estão relacionadas no rol de suas competências, como auxílio na coleta de sangue e substituição de pessoal administrativo na recepção da unidade.

Ainda, sobre as condições de trabalho foi relatado pelos ACS que durante as visitas domiciliares, eles ficam longos períodos nesta atividade externa sem acesso ao banheiro, e que só ocorre ao final da tarde, quando retornam para a unidade de saúde. Consequência disto é que suas necessidades fisiológicas ficam comprometidas, o que ocasionaria distúrbios em sua saúde. Há que se destacar que em muitas situações os ACS não medem esforços para a superação das dificuldades encontradas no cotidiano do trabalho, identificadas por si mesmos, pela equipe e, principalmente pela comunidade.

É evidente a falta de resolubilidade do sistema de saúde que se mostra incapaz de atender as demandas relacionadas aos problemas de saúde da população, não enfrentando com estratégias de prevenção e promoção da saúde os riscos e as vulnerabilidades sociais, intensificadas pela atual conjuntura socioeconômica que agrava ainda mais a pobreza e a desigualdade social. Nesta situação, o ACS é colocado em condição de grande sofrimento, com desgaste emocional, porque cotidianamente assiste ao sofrimento da população, sem ser capaz de dar as respostas que se the pedem todos dos dias, durante as visitas domiciliares. Quando os problemas não podem ser resolvidos, e diante do sofrimento do outro, isso provoca desgaste emocional.

No embate entre a população, que sofre quanto tem seu direito à saúde é negado, e o sistema de saúde, com todas as suas fragilidades, relacionadas principalmente ao subfinanciamento do SUS, - ACS fica dividido: defender a instituição que Ihe paga os salários e garante o "ganha pão" para sua família ou ficar ao lado da população, ajudando a mobilizar a comunidade para exigir seus direitos.

A própria condição de trabalhador, impede o ACS de ir contra a instituição que lhe dá o sustento, forçando a tomar atitudes em favor da manutenção do sistema com justificativas vazias com vistas a apaziguar o crescente descontentamento da população: "a cidade é grande e a demanda por saúde enorme, por isto demora a marcação das consultas".

Esta pesquisa tem o papel importante de chamar a atenção para o sofrimento patogênico dos ACS, relacionado ao contexto da organização do trabalho, indicando estratégias de cuidados à saúde destes trabalhadores, o que certamente ajudará a melhorar a atenção à saúde da população na Estratégia Saúde da Família.

O tema da saúde dos ACS não se esgota, pelo contrário, fica evidente a necessidade de se ampliar o olhar sobre os motivos de adoecimento desses profissionais, que talvez não tenham sido abordados nesta pesquisa, aqueles relacionados ao papel de cuidador da saúde da população. Outro aspecto que pode ser aprofundado em futuros trabalhos é a vinculação do ACS com a população e sua condição de morador do território em que trabalha. Esta pesquisa poderá subsidiar a proposição de estratégias de cuidados para os trabalhadores em sofrimento patogênico adaptadas ao contexto da organização do trabalho, além de intensificar as reflexões sobre a organização do processo de trabalho na Estratégia Saúde da Família.

\section{REFERÊNCIAS}

ALMEIDA, P. Núcleo de apoio às equipes de saúde da família (NASF): uma breve reflexão. Trabalho de conclusão de curso (Especialização em Atenção Básica em Saúde da Família). Universidade Federal de Minas Gerais - UFMG, Guanhães: 2009

ALONSO, C. M. C.; BEGUIN, P. D.; DUARTE, F.J.C.M. Trabalho dos agentes comunitários de saúde na Estratégia Saúde da família: metassíntese. Rev. de Saúde Pública, vol. 52, São Paulo, 2018. 
ANDRADE, G.O.; DANTAS, R.A.A. Transtornos mentais e do comportamento relacionados ao trabalho em médicos anestesiologistas. Rev. Bras Anestesiol, v. 65, n. 6, p. 504-510, 2015. https://doi.org/10.1016/i.bjan.2013.03.021

ANDRADE, F.M.O. O Programa de Saúde da Família no Ceará. Dissertação (Mestrado em Saúde Pública). Universidade Federal do Ceará. Fortaleza. 1998.

AVILA, M. M. M. O Programa de Agentes Comunitários de Saúde no Ceará: o caso de Uruburetama. Ciênc. saúde coletiva, v.16, n.1, p.349-360, 2011.

https://doi.org/10.1590/S1413-81232011000100037

AZAMBUJA, E.P.; FERNANDES, G.F.M.; KERBER, N.P.C.; SILVEIRA, R.S.S.; SILVA, A.L.; GONCALVES, L.H.T.; CARTANA, M.H.F. Significados do trabalho no processo de viver de trabalhadoras de um programa de saúde da família. Texto Contexto Enferm, 16 (1): 71-9, 2007. Disponível em: <http://www.scielo.br/pdf/tce/v16n1/a09v16n1.pdf>. https://doi.org/10.1590/S0104-07072007000100009

BERNARDES, K. A. G. Qualidade de vida de agentes comunitários de saúde de um município da região oeste do estado de São Paulo. Dissertação (Mestrado) Escola de Enfermagem de Ribeirão Preto, Universidade de São Paulo, Ribeirão Preto: 2008, 79 f.

BRASIL. 8ª Conferência Nacional de Saúde. Ministério da Saúde. Brasília, DF: Senado Federal. 1986. Disponível em:

<http://bvsms.saude.gov.br/bvs/publicacoes/8_conferencia_nacional_saude_relatorio_final.pdf>.

Programa Agentes Comunitários de Saúde - PACS. Brasília: Ministério da Saúde.

2001.

Lei n. 10.507 de 10 de julho de 2002. Cria a profissão de Agente Comunitário de Saúde e dá outras providências. Ministério da Saúde. Secretaria de Políticas de Saúde. Brasília: 2002.

Portaria n. 44, de 3 de janeiro de 2002. Define as atribuições dos agentes comunitários de saúde no controle e prevenção da malária e da dengue. Ministério da Saúde. Diário Oficial da República Federativa do Brasil, Brasília; 08 jan. 2002.

. Legislação do SUS. Conselho Nacional de Secretários de Saúde. Brasília : CONASS, $\overline{2003.604}$ p. Disponível em:

<http://bvsms.saude.gov.br/bvs/publicacoes/progestores/leg_sus.pdf $>$.

3. a Conferência Nacional de Saúde do Trabalhador: "trabalhar, sim! adoecer, não!": coletânea de textos. Brasília: Ministério da Saúde, 2005.

Legislação em saúde: caderno de legislação em saúde do trabalhador. $2^{a}$.ed. rev. e ampl. Ministério da Saúde, Brasília: 2005, 380p.

Política Nacional de Atenção Básica. Ministério da Saúde. Brasília; 2006

Lei $\mathrm{n}^{\circ} 11.350$, de 5 de outubro de 2006. Regulamenta o $\S 5^{\circ}$ do art. 198 da Constituição, dispõe sobre o aproveitamento de pessoal amparado pelo parágrafo único do art. $2^{\circ}$ da Emenda Constitucional ํㅡ 51, de 14 de fevereiro de 2006, e dá outras providências. Diário Oficial [da] República Federativa do Brasil, Brasília-DF, 6 out. 2006b. Disponível em: <http://www.planalto.gov.br/ccivil 03/ ato2004-2006/2006/lei/l11350.html>. Acesso em: 15 de mar. 2018.

Diretrizes do Núcleo de Apoio a Saúde da Família (NASF). Ministério da Saúde. Cadernos de Atenção Básica, n.27, (Série B. Textos Básicos de Saúde). Brasília: 2009. 
CARVALHO, V.L.M. A prática do Agente Comunitário de Saúde: um estudo sobre sua dinâmica social no município de Itapecerica da Serra. Dissertação [Mestrado]. São Paulo: Faculdade de Saúde Pública, Universidade de São Paulo; 2002.

DEJOURS, C.; ABDOUCHELI, E.; JAYET, C. (Org.). Psicodinâmica do trabalho. São Paulo: Atlas. 1994.

DEJOURS, C. A Loucura do Trabalho: Estudo de Psicopatologia do Trabalho. São Paulo: Cortez, 1987.

DEJOURS, C. Conferencias brasileira: Identidade, Reconhecimento e Transgressão. Fundap Easp. FGV, São Paulo: 1999.

SILVA, E. R.P.; CAZOLA, L. H. O.; CHEADE, M. F. M. Atuação dos Agentes Comunitários de Saúde na Estratégia Saúde da Família. Cogitare Enferm, v. 17, v. 4, p. 635-644, 2012. https://doi.org/10.5380/ce.v17i4.30359

FERRAZ, L.; AERTS, D.R.G.C. O cotidiano de trabalho do agente comunitário de saúde no PSF em Porto Alegre. Ciênc. saúde coletiva, Rio de Janeiro, v. 10, n. 2, p. 347- 355, 2005. https://doi.org/10.1590/S1413-81232005000200012

FLICK, U. Introdução à pesquisa qualitativa. Porto Alegre: Artmed. 2008.

FREITAS, L. G. de; FACAS, E. P. Vivências de prazer-sofrimento no contexto de trabalho dos professores. Estud. pesqui. psicol., Rio de Janeiro , v. 13, n. 1, p. 7-26, abr. 2013. https://doi.org/10.12957/epp.2013.7880

IBGE. Estimativas da população residente nos municípios brasileiros. Instituto Brasileiro de Geografia e Estatística. Diretoria de Pesquisa, 2017

KEBIAN, L.V.A.; ACIOLI, S. Visita domiciliar: espaço de práticas de cuidado do enfermeiro e do Agente Comunitário de Saúde. Rev. enferm. UERJ, Rio de Janeiro; v. 19, n. 3, p. 403- 409, 2011.

KLUTHCOVSKY, A. C. G. C. Qualidade de vida dos agentes comunitários de saúde de um município do interior do Paraná. Dissertação (Mestrado) Escola de Enfermagem de Ribeirão Preto, Universidade de São Paulo, Ribeirão Preto, 2005, 118 f.

LACAZ, F. A. de C. O campo saúde do trabalhador: resgatando conhecimentos e práticas sobre as relações trabalho-saúde. Caderno Saúde Pública, v. 23, n. 4, p. 757-766, 2007. https://doi.org/10.1590/S0102-311X2007000400003

LAURELL, A. A saúde-doença como processo social. Revista Latino-americana de Salud, v. 2, p. 7-25, 1982.

LAURELL A.C.; NORIEGA, M. Processo de produção e saúde: trabalho e desgaste operário. São Paulo (SP): Hucitec. 1989.

LIMA, J.M.; QUEIROZ, M.D.; LOPES, G.P.; SANTOS, V.C.P. Promovendo a saúde mental dos agentes comunitários de saúde - oficina de depressão x bem-estar: um relato de experiência. Anais. XV Seminário de Iniciação Científica. 17 a 21 de outubro de 2011. Universidade Estadual de Feira de Santana. Feira de Santana: 2011. Disponível em: http://www.xvsemic.esy.es/upload/2011/2011XV-039JAN636-220.pdf.

LINO, M. M.; LANZONI, G. M. M.; ALBUQUERQUE, G. L.; SCHVEITZER, M. C. Perfil socioeconômico, demográfico e de trabalho dos Agentes Comunitários de Saúde. Cogitare Enferm. 17(1): 57-64, 2012. https://doi.org/10.5380/ce.v17i1.26375 
LOPES, D. M. Q.; BECK, C. L. C.; PRESTES, F. C.; WEILLER, T. H.; COLOMÉ, J. S.; SILVA, G. M. Agentes Comunitários de Saúde e as vivências de prazer - sofrimento no trabalho: estudo qualitativo. Rev Esc Enferm USP, v. 46, n. 3, p. 633-640, 2012. https://doi.org/10.1590/S0080$\underline{62342012000300015}$

MACHADO, L. M; MATTOS, K. M, COLOMÉ, J. S, FREITAS N. Q, SANGOI, T. P. Estratégia saúde da família: A percepção do agente comunitário de saúde quanto a sua atuação. Cienc Cuid Saude. 14(2):1105-1112, 2015. https://doi.org/10.4025/cienccuidsaude.v14i2.22612

MANZINI, E. J. A entrevista na pesquisa social. Didática, São Paulo, v. 26/27, p. 149-158, 199c1.

MARTINS, C. L.; OLIVEIRA, L. S. S.; RODRIGUES, M. A.; WATANABE, H. A. W.; JACOMO, Y. A. Agentes comunitários nos serviços de saúde pública: elementos para uma discussão. Revista Saúde Debate. v. 51, p. 38-43, 1996.

MINAYO, M. C. S. (Org.). Pesquisa social: teoria, método e criatividade. Petrópolis: Vozes, 2001.

MINAYO, M. C. S. O Desafio do Conhecimento: Pesquisa Qualitativa em Saúde. 10ª ed. São Paulo: HUCITEC, 2007.

MORENO, F. N.; GIL, G. P.; HADDAD, M. C. L.; VANNUCHI, M. T. O. Estratégias e Intervenções no Enfrentamento da Síndrome de Burnout. Rev. Enferm. UERJ. Rio de Janeiro, 19(1):140-145, 2010.

ORGANIZAÇÃO MUNDIAL DA SAÚDE. CID-10: Classificação Estatística Internacional de Doenças e Problemas Relacionados à Saúde. 10a rev. São Paulo: Universidade de São Paulo; 1997. vol.1. 5.

QUEIRÓS, A. A. L.; LIMA, L. P. A institucionalização do trabalho do agente comunitário de saúde. Trabalho, Educação e Saúde, v. 10, n. 2, p. 257-281, 2012. https://doi.org/10.1590/S1981$\underline{77462012000200005}$

RAZZOUK, D.; LIMA, M. G. A.; CORDEIRO, Q. (Org.) Saúde mental e trabalho. São Paulo: CREMESP; 2016. 310 p.

REIS, L. B. Uma análise de dimensão ético-política do trabalho de agentes comunitários de saúde do município de Vitória. Dissertação (Mestrado em Psicologia) Centro de Ciências Humanas e Naturais, Universidade Federal do Espírito Santo, Vitória: 2005, 224 f.

ROSA A.J, BONFANTI A.L, CARVALHO, C.S. O sofrimento psíquico de agentes comunitários de saúde e suas relações com o trabalho. Saúde Soc., 21(1):141-52, 2012.

https://doi.org/10.1590/S0104-12902012000100014

SELIGMANN-SILVA, E. Desgaste mental no trabalho dominado. Rio de Janeiro: Editora UFRJ; São Paulo: Cortez, 1994.

SANTANA, M.C.C.de. Avaliação da Qualidade de Vida dos Agentes Comunitários de Saúde da Família de Ipojuca, Pernambuco. 2015. Monografia (Residência em Saúde Coletiva) - Centro de Pesquisas Aggeu Magalhães, Fundação Oswaldo Cruz, Recife, 2015.

SANTOS, L.P.G.S. dos; FRACOLLI, L.A. O Agente Comunitário de Saúde: possibilidades e limites para a promoção da saúde. Rev. Esc. Enferm. USP, São Paulo. v. 44, n. 1, p. 76-83, 2010. https://doi.org/10.1590/S0080-62342010000100011

SILVA J.A.; Dalmaso, A.S.W. Agente Comunitário de Saúde: o Ser, o saber, o fazer. FIOCRUZ. Rio de Janeiro: 2002.https://doi.org/10.7476/9788575416136 
SILVA, A.T.C. da; MENEZES, P.R. Esgotamento profissional e transtornos mentais comuns em agentes comunitários de saúde. Rev. Saúde Pública, São Paulo, v. 42, n. 5, p. 921-929, 2008. https://doi.org/10.1590/S0034-89102008000500019

VASCONCELLOS, N. P.; COSTA-VAL, R. Avaliação da qualidade de vida dos agentes comunitários de saúde de Lagoa Santa-MG. Revista APS, v. 11, n.1, p. 17-28, 2008. 